Int. J. Dev. Biol. 56: 577-582 (2012)

doi: $10.1387 / \mathrm{ijdb} .113472 \mathrm{ab}$

\title{
The Nematocyst: a molecular map of the Cnidarian stinging organelle
}

\author{
ANNA BECKMANN and SUAT ÖZBEK* \\ Department for Molecular Evolution and Genomics, Centre for Organismal Studies, University of Heidelberg, \\ Heidelberg, Germany
}

\begin{abstract}
Nematocysts or cnidocysts represent the common feature of all cnidarians. They are large organelles produced from the Golgi apparatus as a secretory product within a specialized cell, the nematocyte or cnidocyte. Nematocysts are predominantly used for prey capture and defense, but also for locomotion. In spite of large variations in size and morphology, nematocysts share a common build comprising a cylindrical capsule to which a long hollow thread is attached.The thread is inverted and coiled within the capsule and may be armed with spines in some nematocyst types. During the discharge of nematocysts following a chemical or mechanical stimulus, the thread is expelled from within the capsule matrix in a harpoon-like fashion. This process constitutes one of the fastest in biology and is accompanied by a release of toxins that are potentially harmful also for humans. The long history of research on Hydra as a model organism has been accompanied by the cellular, mechanistic and morphological analysis of its nematocyst repertoire. Although representing one of the most complex organelles of the animal kingdom, the evolutionary origin and molecular map of the nematocyst has remained largely unknown. Recent efforts in unraveling the molecular content of this fascinating organelle have revealed intriguing parallels to the extracellular matrix.
\end{abstract}

KEY WORDS: cnidocyst, hydra, morphogenesis, basal metazoa, matrix

\section{Introduction}

Nematocytes or cnidocytes (Fig. 1A) are highly specialized cells that represent a taxonomically restricted feature of the cnidarian clade. They synthesize in their cytoplasm a unique organelle called nematocyst or cnidocyst/cnida (Fig. 1 A-C). Nematocysts are used for predation, as well as for locomotion and defense and, due to their role in predation, are mainly localized in the tentacles, allowing animals of this phylum an efficient prey capture, although they lack a sophisticated central nervous system. While Abraham Trembley in his description of Hydra in 1744 described nematocysts as little light-breaking structures on the tentacles of the animal (Trembley, 1744), the morphology and function of the nematocyst was discovered not until the mid 19th century, after adequate microscopic and histological techniques were developed (Lenhoff and Lenhoff, 1988). A first comprehensive report on nematocyst morphology and species-specific distribution of capsule types was published by Weill in 1934 (Weill, 1934a, Weill, 1934b). The organelle itself can differ in size $(5-100 \mu \mathrm{m})$ and shape (round to cylindrical) but always shows a common built being composed of a wall and an attached tubule, which might be adorned with spines and appendices (Fig. 1 D-E) (Teragawa and Bode, 1995). At the apical end of the cell, a mechanosensory apparatus called cnidocil, a central cilium surrounded by shorter stereocilia, points towards the outside (Fig. 1B) (Hausmann and Holstein, 1985). The nematocyst body is anchored tightly in the cytoplasm of the nematocyte by a microtubule basket surrounding the capsule (Engel et al., 2002).

According to their morphological properties nematocysts can be divided into 25-30 types and thus represent an important feature for taxonomic grouping within the cnidarians (Mariscal, 1974, Weill, 1934a, Weill, 1934b), as the different types of nematocysts are not equally distributed among different species (Fautin, 1988). Within the cnidarian clade, hydrozoans display the highest structural complexity of nematocysts (David et al., 2008). Hydra possesses four different types of capsules (Holstein, 1981): the large stenoteles that exhibit prominent spines at the base of their tubules, the atrichous and holotrichous isorhizas that are used for attachment to surfaces and prey organisms, and the small desmonemes, which coil tightly around appendices of the prey after discharge (Fig. 1C).

In Hydra, nematocytes originate from the neuronal stem cell population and after specification produce the nematocyst (Tardent,

Abbreviations used in this paper: CRD, cysteine-rich domain; ECM, extracellular matrix.

*Address correspondence to: Suat Özbek. COS Heidelberg, Im Neuenheimer Feld 230, 69120 Heidelberg, Germany. e-mail: suat.oezbek@cos.uni-heidelberg.de 
1995). The nematocyst is a product of a complex secretion process and forms within a large post-Golgi vesicle in the cytoplasm of the nematocyte (Slautterback and Fawcett, 1959, Fawcett et al., 1959, Skaer, 1973, Holstein, 1981) (Fig. 1A). Hydra possesses about 100.000 cells, 25.000 of which are nematocytes and 40.000 are in the process of differentiation (David and Challoner, 1974, David and Gierer, 1974). Thus, cnidarians invest a large fraction of their energy into the maintenance of their nematocyst repertoire, which has to be constantly renewed. Nematocytes derive from interstitial stem cells (i-cells) (Bode and David, 1978, see in this issue David, 2012) that undergo up to 5 steps of mitosis, resulting in nests of developing nematocytes called nematoblasts (David and Challoner, 1974). The development of nematocytes takes place in the body column of Hydra. When nematocytes mature they migrate to their destination, mainly into the tentacles, where they are incorporated in battery cells. Upon maturation poly-gamma-glutamate and associated cations are incorporated into the capsule, leading to an extreme osmotic pressure of 150 bar (Weber, 1989, Weber, 1990). Battery cells contain one to two stenoteles and several isorhizas, surrounded by desmonemes (Fig. 1B). The nematocytes contact sensory neurons, which results in a coordinated discharge of this functional unit. The process of discharge is one of the fastest events known in animal kingdom and generates an acceleration of more than 5 million g (Holstein and Tardent, 1984, Nuchter et al., 2006). During discharge, the spines thrust through the opened operculum and the inverted coiled tubule is everted to the outside (Fig. $1 \mathrm{D}-\mathrm{E})$. This process is accompanied by the release of soluble neurotoxins into the tissue of a prey organism (Ozbek et al., 2009). The secretion of molecules with toxic function might therefore have been at the base of nematocyst evolution (see in this issue Rachamim and Sher, 2012).
In the present review we focus on the molecular aspects of nematocyst morphogenesis in Hydra that has served as a model for nematocyst research for decades. A recent proteome analysis of the Hydra cnidom performed in our laboratory has confirmed the notion of a specialized ECM with both, stress-resistant and elastic properties, as a basis of the nematocyst capsule structure (Özbek, 2010) (Balasubramanian et al., 2012). Nematocyst evolution might therefore have been tightly linked to ECM evolution in Hydra and other cnidarians (see in this issue Sarras, 2012).

\section{Nematocyst morphogenesis in Hydra}

In Hydra, nematocyst-synthesizing cells are produced continuously from the multipotent interstitial stem cell lineage (named i-cells), which in addition gives rise to neurons, gland cells, and germ cells (Bosch and David, 1991, Fujisawa et al., 1986, Shimizu and Bode, 1995, Teragawa and Bode, 1995). Nematocyst specification and morphogenesis takes place in the body column of Hydra, where i cells committed to the nematoblast pathway undergo 3-5 divisions resulting in clusters or nests of 8-32 cells (Fig. 3C) that are connected to each other by cytoplasmic bridges (Slautterback and Fawcett, 1959). Nematocyst synthesis during this phase starts by the formation of a vesicle primordium, which then grows by continuous feeding with further secretory vesicles from the Golgi apparatus (Holstein, 1981) (Fig. 1A). The vesicles contain secreted proteins that are assembled within the growing nematocyst vesicle to form a lattice or matrix-like structure, which will constitute the capsule wall.

Capsule wall formation precedes tubule morphogenesis, which is initiated by membrane tubulation at the apical site of the nematocyst vesicle (Fig. 1A) (Adamczyk et al., 2010). As outlined below
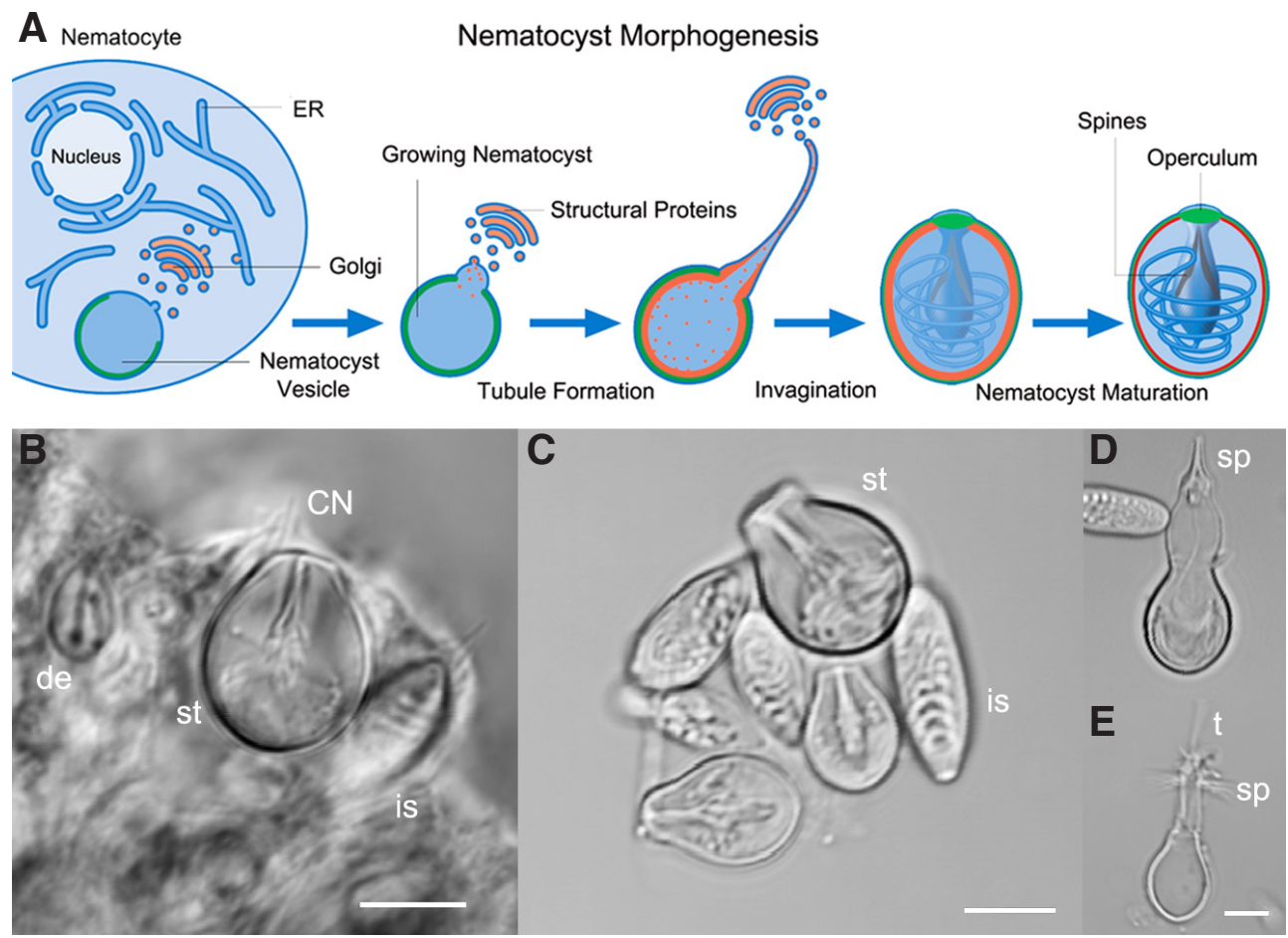

Fig. 1. Nematocyst morphogenesis. (A) Schematic representation of nematocyst morphogenesis. Nematocyst formation takes place in the cytoplasm of the nematocyte (cnidocyte). The nematocyst vesicle grows by addition of protein filled vesicles from the Golgi apparatus. Tubule formation is initiated by membrane tubulation at the apical site of the nematocyst vesicle. After completion, the tubule is invaginated into the capsule matrixand the capsule is closed bya lid structure (operculum). Spines decorating the tubule are added after invagination. Nematocyst maturation involves capsule wall compaction by polymerization of structural proteins, e.g. minicollagens. Adapted from Spektrum derWissenschaft, May2008, Wie Proteine der Evolution Brücken bauen, p.4. (B) A battery cell in the tentacle of Hydra harbouring a central stenotele (st) surrounded by isorhizas (is) and desmonemes (de). The cnidocil (CN) points towards the outside and gets detached after nematocyst isolation. (C) Isolated undischarged nematocysts with clearly visible coiled tubules in the capsule matrices. (D) Incompletely discharged stenotele. Mark that the tubule still resides within the capsule and the spines (sp) have been thrust forward by the initial discharge step. (E) Fully discharged stenotele with empty capsule body. The spines are folded back and the tubule (t) is expelled. Scale bars, $5 \mu$ m. 
this process involves molecular components that in part are stored within the capsule matrix or enter the nematocyst vesicle only at later stages of development (Adamczyk et al., 2008). After having reached their full length, tubules invaginate by a poorly understood mechanism and are tightly coiled within the capsule body. Tubule invagination initiates capsule maturation, which involves wall compaction and hardening (Fig. 1A) (Engel et al., 2001). Nematocyst morphogenesis is synchronised in cells forming a syncytial cluster or nest until final maturation. When reaching maturation, the nematocyte nests break up into single cells that start migrating along the epithelial cells towards the tentacles (Campbell and Marcum, 1980). The maturation step is clearly detectable by in situ hybridization experiments for structural molecular components of the nematocyst (Adamczyk et al., 2008, Engel et al., 2001). Gene expression for these molecules is restricted to the body column of the animal and terminated at a sharp border below the head (see also in this issue Böttger and Hassel, 2012). In the tentacles mature nematocysts are incorporated into large battery cells that harbor several types of capsules in a close arrangement (Fig. 1B).

Nematocyst morphogenesis is a continuous process in cnidarians, as the organelles have to be replaced after discharge. Commitment of progenitor cells to a particular type of nematocyst takes place during the terminal cell cycle of "small" i-cells forming nematoblast nests (Fujisawa and David, 1981, Fujisawa and David, 1982, Fujisawa et al., 1986).

\section{Molecular components of the nematocyst capsule body}

The first structural nematocyst molecules identified in isolated capsules from Hydra were of collagenous nature and termed minicollagens due to the unique shortness of their collagen triple helices (Lenhoff et al., 1957, Kurz etal., 1991, Holstein et al., 1994). Minicollagens are expressed from the early stages of nematocyst morphogenesis until capsule maturation and thus allow a detailed monitoring of capsule development (Engel et al., 2001). Hydra minicollagen-1 (NCol-1), which is the most conserved member of the family, possessing close homologs in all other cnidarians analyzed so far, is exclusively restricted to the capsule wall of the organelle and does not contribute to tubule structures (Engel et al., 2001). This is not only evident from antibody stainings, but also from transgenic animals expressing minicollagen-1-GFP fusion molecules under the control of a nematocyst-specific promotor (Fig. 3A). As different minicollagens show a restricted distribution to wall or tubule structures (Adamczyk et al., 2008) domain duplication and variation processes predominantly in non-collagen domains appear to have resulted in functional differentiation in minicollagens (David et al., 2008).

Minicollagens are unique and ancient trademarks of cnidarians and comprise common domain architectures (Fig. 2): the central collagen repeat extends into polyproline stretches of variable length and is terminated at both ends by short cysteine-rich domains (CRD) with a conserved cysteine pattern of 6 cysteines in a total number of 18 amino acids (Özbek et al., 2002a). The CRDs represent a rare case of structural variation in closely related protein sequences with the $\mathrm{N}$-terminal CRDs exhibiting a dramatically different three-dimensional structure compared to the C-terminal CRDs (Meier et al., 2007). Most minicollagens thus exhibit a polarized molecular architecture, which probably is a prerequisite for correct macromolecular assembly (Fig. 2).

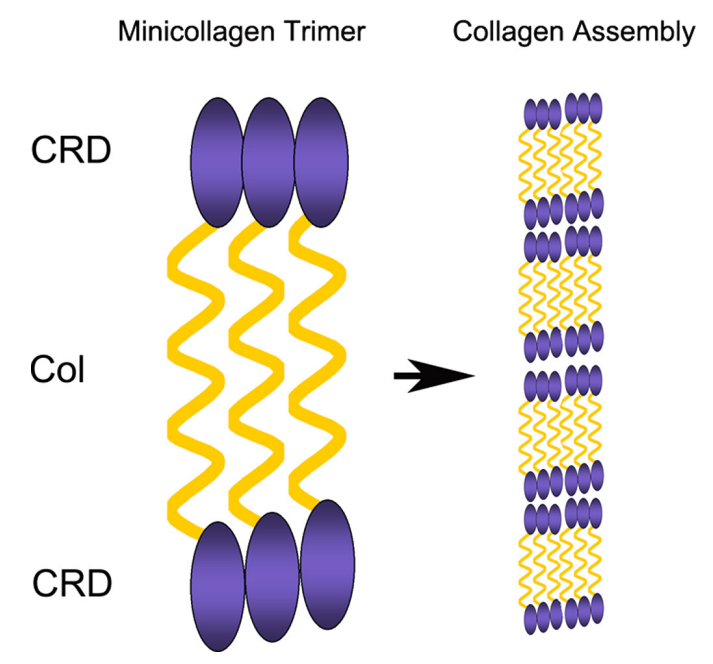

Fig. 2. Schematic representation of minicollagens. During nematocyst maturation the trimeric minicollagens associate via their terminal cysteinerich domains (CRD) forming a stress-resistant supra-structure.

In immature nematocysts within developing nematocyte nests minicollagens are still in a soluble state and can be extracted as monomers (Engel et al., 2001). After maturation they are integrated into the highly compacted supra-structure of the capsule wall by a disulfide-dependent process (Özbek et al., 2002b). It is assumed that a disulfide reshuffling process generates multiple intermolecular cysteine links between different minicollagens. Zenkert et al., have recently demonstrated that in nematocysts of the starlet sea anemone Nematostella vectensis minicollagens are stabilized by further covalent cross-links, which are absent in Hydra (Zenkert et al., 2011). Such intermolecular crosslinks are characteristic for fibrillar collagens in vertebrates and might therefore indicate a common evolutionary origin between minicollagens and ECM collagens.

\section{Tubule morphogenesis is dependent on protein-carbo- hydrate interactions}

Tubule morphogenesis can be divided into four different stages: protrusion, outgrowth, invagination and compaction (Fig. 1A). The first steps of tubule development involve a membrane protrusion of the growing nematocyst vesicle at the apical end surrounded by the trans-Golgi-network. This tubulation process is connected to rearrangements of the actin and tubulin cytoskeleton and probably membrane-associated cytoplasmic factors.

The tubule represents the most elaborate and innovative structure of the nematocyst. Capsule type classification often depends exclusively on the phenotypes of the respective tubules, which can be adorned with spines in varying arrays and dimensions and reach lengths of up to several hundred $\mu \mathrm{m}$. Tubule spines serve for different functions, depending on the capsule type, and are of high mechanical stability. The large stylets at the tubule base of stenoteles (Fig. $1 \mathrm{D}-\mathrm{E}$ ) are used to puncture protective cuticles and shells of prey organisms, while the smaller spines of desmonemes and isorhizas help in attaching Hydra to the prey or substrate. Several exclusive tubule components have already been identified demonstrating that the morphological distinction from the capsule body is also reflected by a specialized composition on the molecular level. 

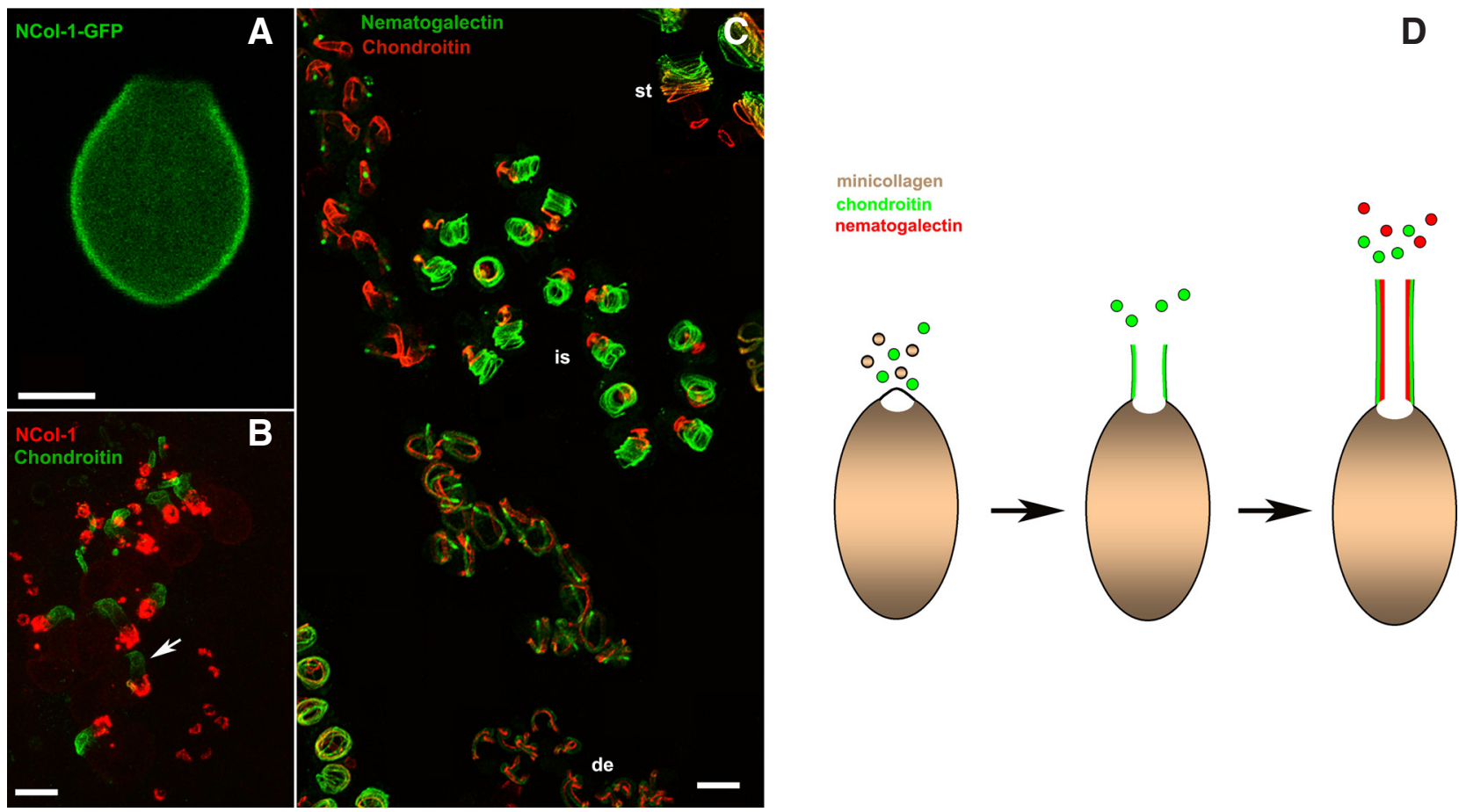

Fig. 3. Molecular components of the nematocyst. (A) Isolated mature stenotele from transgenic Hydra expressing a minicollagen-1-GFP fusion protein under control of a nematocyte-specific promotor. (B) Nest of developing nematocysts stained with minicollagen-1 (red) and chondroitin (green) antibodies. The growing tubule is covered with a chondroitin matrix (arrow). At its apical end minicollagen-1 molecules are present in vesicles of the trans-Golgi-network that fuse with the nematocyst vesicle releasing their content into the capsule matrix. (C) Nest of nematocysts at different developmental stages and of different types stained with chondroitin (red) and nematogalectin (green) antibodies. Both molecules are part of the tubule covering different surfaces of its structure. The nematogalectin signal is stronger after invagination as it covers the inner layer of the growing tubule, which then is turned to the outside. st, stenoteles; is, isorhizas; de, desmonemes. (D) Schematic representation of tubule formation by the sequential addition of tubule-specific factors. Nematocyst-specific chondroitin and nematogalectin form different layers of the growing tubule while minicollagen-1 is produced earlier and incorporated into the capsule wall structure. Scale bars, $5 \mu \mathrm{m}$.

Spinalin, a glycine- and histidine-rich protein, has been characterized as a spine component that is added to tubules after invagination (Hellstern et al., 2006, Koch et al., 1998). During early morphogenesis spinalin accumulates as large protein bodies in the capsule matrix forming a depot for later tubule maturation (Adamczyk et al., 2008). Spinalin is related to loricrins and cytokeratins and therefore believed to form similar insoluble and resistant structures (Koch et al., 1998).

Minicollagen-15 (NCol-15) is the first member of the minicollagen family showing an exclusive localization to the tubule structure (Adamczyk et al., 2008). Similar to spinalin NCol-15 is stored in the capsule matrix until tubule invagination and then incorporated during further maturation. On the sequence level, a duplicated Cterminal CRD with a deviated cysteine pattern distinguishes $\mathrm{NCol}$ 15 from NCol-1. As a consequence of this sequence deviation the C-terminal NCol-15 CRD adopts a different three-dimensional fold, which probably precludes incorporation into the capsule wall matrix.

Recently, two novel molecular tubule components have been described that appear to have a complementary pattern and accompany tubule morphogenesis from the very early onset: the galactose-binding lectin nematogalectin and a nematocyst-specific chondroitin. Adamczyk et al., have shown that tubule elongation depends on the presence of a glycosaminoglycan, an unusual non-sulfated chondroitin that forms a scaffold structure along the outer surface of the tubule (Adamczyk et al., 2010) (Fig. 3B-D). The nematocyst-specific chondroitin is essential for tubule elongation as inhibition of glycosaminoglycan synthesis by xylosides arrests nematocyst morphogenesis at different stages of tubule elongation and leads to a complete depletion of mature capsules in the treated animals (Adamczyk et al., 2010). Asimilar chondroitin-based matrix has been described for neuronal cells, in which a chondroitin-rich perineuronal net forms a specialized ECM around cell protrusions (Celio et al., 1998).

The chondroitin-based matrix is closely associated with a nematocyst-specific lectin that comprises a conserved $\mathrm{N}$-terminal domain, followed by GlyXY repeats that form a collagen triple helix, a C-terminal galactose binding lectin and a basic domain (Fig. 3 C-D) (Hwang et al., 2010). Alternative splicing yields two variants of nematogalectin, which are differentially expressed: while nematogalectin $A$ is located at tubules of stenoteles and isorhizas, nematogalectin $\mathrm{B}$ occurs predominantly in tubules of desmonemes. Nematogalectin is closely associated with chondroitin and lines the inner surface of the growing tubule that gets exposed to the surface after invagination (Fig. 3C). The fact that its expression pattern is matched with that of chondroitin suggests a close molecular interaction between these molecules. It has been speculated therefore that nematogalectins might play a role in the assembly of minicollagens during later maturation and form a linker molecule between the GAG and the collagen matrices (Adamczyk et al., 2010, Hwang et al., 2010). Thus, the tubule might be synthesized as a lectin-glycosaminoglycan-based scaffold, which is stabilized by minicollagens after invagination. Our proteome 
analysis has yielded a high number of further lectin-type proteins as components of the capsule (Balasubramanian et al., 2012). We therefore assume that protein-carbohydrate interactions play a major role in the capsule assembly.

\section{Conclusion}

The structural composition of the cnidarian nematocyst shows clear similarities to the extracellular matrix of metazoans. Minicollagens, lectins and glysominoglycans are prominent examples and have an essential role in nematocyst morphogenesis. We therefore postulate an evolutionary scenario in which cells secreting soluble toxins acquired ECM components for more efficient delivery and probably storage of toxins. In addition, many protein toxins, like toxic lectins, are related to ECM molecules (Eble, 2010) and might have contributed to the structural part of the nematocyst proteome. A detailed comparison between the nematocyst proteomes of different cnidarian species will help in defining the evolutionary history of this organelle. Our proteome data clearly point towards a conserved set of the soluble, toxin-related genes to which structural proteins were added in species-specific variations (Balasubramanian et al., in revision).

\section{Acknowledgements}

We thank Brigitte Galliot for many helpful suggestions and critical reading. Our work is supported by DFG grants to S.Ö.

\section{References}

ADAMCZYK, P., MEIER, S., GROSS, T., HOBMAYER, B., GRZESIEK, S., BACHINGER, H.P., HOLSTEIN, T.W., OZBEK, S. (2008). Minicollagen-15, a novel minicollagen isolated from Hydra, forms tubule structures in nematocysts. $J \mathrm{Mol}$ Biol 376: 1008-1020.

ADAMCZYK, P., ZENKERT, C., BALASUBRAMANIAN, P.G., YAMADA, S., MURAKOSHI, S., SUGAHARA, K., HWANG, J.S., GOJOBORI, T., HOLSTEIN, T.W., OZBEK, S. (2010). A non-sulfated chondroitin stabilizes membrane tubulation in cnidarian organelles. J Biol Chem 285: 25613-25623.

BALASUBRAMANIAN P.G., BECKMANN A., WARNKEN U., SCHNOELZER M., SCHUELER A., BORNBERG-BAUER E., HOLSTEIN T.W., OZBEK S. (2012). The proteome of the hydra nematocyst. J Biol Chem. 287: 9672-9681. (DOI: 10.1074/jbc.M111.328203).

BODE, H.R., DAVID, C.N. (1978). Regulation of a multipotent stem cell, the interstitial cell of hydra. Prog Biophys Mol Biol 33: 189-206.

BÖTTGER, A. and HASSEL, M. (2012). Hydra, a model system to trace the emergence of boundaries in eumetazoans. Int J Dev Biol 56: 583-591.

BOSCH, T.C., DAVID, C.N. (1991). Decision making in interstitial stem cells of Hydra. In vivo 5: 515-520.

CAMPBELL, R.D., MARCUM, B.A. (1980). Nematocyte migration in Hydra: evidence for contact guidance in vivo. J Cell Sci 41: 33-51.

CELIO, M.R., SPREAFICO, R., DE BIASI, S., VITELLARO-ZUCCARELLO, L. (1998). Perineuronal nets: past and present. Trends Neurosci 21: 510-515.

DAVID, C.N. (2012). Interstitial stem cells in Hydra: multipotency and decision-making. Int J Dev Biol 56: 489-497.

DAVID, C.N., CHALLONER, D. (1974). Distribution of interstitial cells and differentiating nematocysts in nests in Hydra attenuata. Am Zool 14: 537-542.

DAVID, C.N., GIERER, A. (1974). Cell cycle kinetics and development of Hydra attenuata. III. Nerve and nematocyte differentiation. J Cell Sci 16: 359-75.

DAVID, C.N., OZBEK, S., ADAMCZYK, P., MEIER, S., PAULY, B., CHAPMAN, J., HWANG, J.S., GOJOBORI, T., HOLSTEIN, T.W. (2008). Evolution of complex structures: minicollagens shape the cnidarian nematocyst. Trends Genet 24: 431-438.

EBLE, J.A. (2010). Matrix biology meets toxinology. Matrix Biol 29: 239-247.

ENGEL, U., OZBEK, S., ENGEL, R., PETRI, B., LOTTSPEICH, F., HOLSTEIN, T.W.
(2002). NOWA, a novel protein with minicollagen Cys-rich domains involved in nematocyst formation in Hydra. J Cell Sci 115: 3923-3934.

ENGEL, U., PERTZ, O., FAUSER, C., ENGEL, J., DAVID, C.N., HOLSTEIN, T.W. (2001). A switch in disulfide linkage during minicollagen assembly in Hydra nematocysts. EMBO J 20: 3063-3073.

FAUTIN, D.G. (1988). Importance of nematocysts to actinian taxonomy, in: The Biology of Nematocysts. HESSINGER, D.A., LENHOFF, H.M., Academic Press, London, pp. 487-500.

FAWCETT, D.W., ITO, S., SLAUTTERBACK, D. (1959). The occurrence of intercellular bridges in groups of cells exhibiting synchronous differentiation. $J$ Biophys Biochem Cytol 5: 453-460.

FUJISAWA, T., DAVID, C.N. (1981). Commitment during nematocyte differentiation in Hydra. J Cell Sci 48: 207-222.

FUJISAWA, T., DAVID, C.N. (1982). Commitment during stenotele differentiation in Hydra is localized near the S/G2 boundary in the terminal cell cycle. Dev Biol 93: 226-230.

FUJISAWA, T., NISHIMIYA, C., SUGIYAMA, T. (1986). Nematocyte differentiation in Hydra. Curr Top Dev Biol 20: 281-290.

HAUSMANN, K., HOLSTEIN, T. (1985). Bilateral symmetry in the cnidocil-nematocyst complex of the freshwater medusa Craspedacusta sowerbii Lankester (Hydrozoa, Limnomedusae). J Ultrastruct Res 90: 89-104.

HELLSTERN, S., STETEFELD, J., FAUSER, C., LUSTIG, A., ENGEL, J., HOLSTEIN, T.W., OZBEK, S. (2006). Structure/function analysis of spinalin, a spine protein of Hydra nematocysts. FEBS J 273: 3230-3237.

HOLSTEIN, T. (1981). The morphogenesis of nematocytes in Hydra and Forskalia: an ultrastructural study. J Ultrastruct Res 75: 276-290.

HOLSTEIN, T., TARDENT, P. (1984). An ultrahigh-speed analysis of exocytosis: nematocyst discharge. Science 223: 830-833.

HOLSTEIN, T.W., BENOIT, G.M., HERDER, G.V., WANNER, G., DAVID, C.N., GAUB H.E. (1994). Fibrous Mini-Collagens in Hydra Nematocysts. Science 265: 402-404.

HWANG, J.S., TAKAKU, Y., MOMOSE, T., ADAMCZYK, P., OZBEK, S., IKEO, K. KHALTURIN, K., HEMMRICH, G., BOSCH, T.C., HOLSTEIN, T.W. et al., (2010). Nematogalectin, a nematocyst protein with GlyXY and galectin domains, demonstrates nematocyte-specific alternative splicing in Hydra. Proc Natl Acad Sci USA 107: 18539-18544.

KOCH, A.W., HOLSTEIN, T.W., MALA, C., KURZ, E., ENGEL, J., DAVID, C.N. (1998) Spinalin, a new glycine- and histidine-rich protein in spines of Hydra nematocysts. J Cell Sci 111: 1545-1554

KURZ, E.M., HOLSTEIN, T.W., PETRI, B.M., ENGEL, J., DAVID, C.N. (1991). Minicollagens in Hydra nematocytes. J Cell Biol 115: 1159-1169.

LENHOFF, H.M., KLINE, E.S., HURLEY, R. (1957). A hydroxyproline-rich, intracellular, collagenlike protein of Hydra nematocysts. Biochim. Biophys. Acta 26: 204-205.

LENHOFF, H.M., LENHOFF, S.G. (1988). Trembley's Polyps. Scientific American 258: 108-113.

MARISCAL, R.N. (1974). Experimental marine biology. Academic Press, New York,

MEIER, S., JENSEN, P.R., DAVID, C.N., CHAPMAN, J., HOLSTEIN, T.W., GRZESIEK, S., ÖZBEK, S. (2007). Continuous molecular evolution of protein-domain structures by single amino acid changes. Curr Biol 17: 173-178.

NUCHTER, T., BENOIT, M., ENGEL, U., OZBEK, S., HOLSTEIN, T.W. (2006) Nanosecond-scale kinetics of nematocyst discharge. Curr Biol 16: R316-318.

ÖZBEK, S. (2010). The cnidarian nematocyst: a miniature extracellular matrix within a secretory vesicle. Protoplasma 248: 635-640

OZBEK, S., BALASUBRAMANIAN, P.G., HOLSTEIN, T.W. (2009). Cnidocyst structure and the biomechanics of discharge. Toxicon 54: 1038-1045.

ÖZBEK, S., ENGEL, U., ENGEL, J. (2002a). A switch in disulfide linkage during minicollagen assembly in Hydra nematocysts or how to assemble a 150-bar-resistant structure. J Struct Biol 137: 11-14.

ÖZBEK, S., PERTZ, O., SCHWAGER, M., LUSTIG, A., HOLSTEIN, T., ENGEL, J. (2002b). Structure/function relationships in the minicollagen of Hydranematocysts. J Biol Chem 277: 49200-49204.

RACHAMIM, T., SHER, D. (2012). What Hydra can teach us about chemical ecology - how a simple, soft organism survives in a hostile aqueous environment. Int J Dev Biol 56: 605-611.

SARRAS, M. P. J. (2012). Components, structure, biogenesis and function of the 
Hydra extracellular matrix in regeneration, pattern formation and cell differentiation. Int J Dev Biol 56: 567-576.

SHIMIZU, H., BODE, H.R. (1995). Nematocyte differentiation in Hydra: commitment to nematocyte type occurs at the beginning of the pathway. Dev Biol 169: 136-150.

SKAER, R.J. (1973). The secretion and development of nematocysts in a siphonophore. J Cell Sci 13: 371-393.

SLAUTTERBACK, D.B., FAWCETT, D.W. (1959). The development of the cnidoblasts of Hydra; an electron microscope study of cell differentiation. J Biophys Biochem Cytol 5: 441-452.

TARDENT, P. (1995). The cnidarian cnidocyte, a hightech cellular weaponry. Bioessays 17: 351-362.

TERAGAWA, C.K., BODE, H.R. (1995). Migrating interstitial cells differentiate into neurons in Hydra. Dev Biol 171: 286-293.

TREMBLEY, A. (1744). Mémoires pour servir à l'histoire d'un genre de polypes d'eau douce à bras en forme de cornes. Jean \& Herman Verbeek, Leiden.

WEBER, J. (1989). Nematocysts (stinging capsules of Cnidaria) as Donnan-potentialdominated osmotic systems. Eur J Biochem 184: 465-476.

WEBER, J. (1990). Poly(gamma-glutamic acid)s are the major constituents of nematocysts in Hydra (Hydrozoa, Cnidaria). J Biol Chem 265: 9664-9669.

WEILL, R. (1934a). Contribution à l'étude des cnidaires et de leurs nématocystes. I. Recherches sur les nématocystes (morphologie, physiologie, développement). pp. 1-347, Travaux Station Zoologie de Wimereux, Bordeaux.

WEILL, R. (1934b). Contribution à l'étude des cnidaires et de leurs nématocystes. II. Valeur taxonomique du cnidome. pp. 351-701. Travaux Station Zoologie de Wimereux, Bordeaux.

ZENKERT, C., TAKAHASHI, T., DIESNER, M.O., OZBEK, S. (2011). Morphological and molecular analysis of the Nematostella vectensis cnidom. PLoS One 6: e22725. 


\section{Further Related Reading, published previously in the Int. J. Dev. Biol.}

A polymorphic, thrombospondin domain-containing lectin is an oocyte marker in Hydractinia: implications for germ cell specification and sex determination

Brahim Mali, R. Cathriona Millane, Günter Plickert, Marcus Frohme and Uri Frank

Int. J. Dev. Biol. (2011) 55: 103-108

An organizing region in metamorphosing hydrozoan planula larvae - stimulation of axis formation in both larval and in adult tissue Melanie Stumpf, Britta Will, Karola Wittig, Jennifer Kasper, Benjamin Fischer, Jürgen Schmich, Stefanie Seipp and Thomas Leitz Int. J. Dev. Biol. (2010) 54: 795-802

Wnt signaling in hydroid development: ectopic heads and giant buds induced by GSK-3beta inhibitors Werner Müller, Uri Frank, Regina Teo, Ofer Mokady, Christina Guette and Günter Plickert Int. J. Dev. Biol. (2007) 51: 211-220

Metamorphosis of Hydractinia echinata (Cnidaria) is caspase-dependent Stefanie Seipp, Karola Wittig, Beate Stiening, Angelika Böttger and Thomas Leitz Int. J. Dev. Biol. (2006) 50: 63-70

The role of alpha-amidated neuropeptides in hydroid development--LWamides and metamorphosis in Hydractinia echinata

Günter Plickert, Eva Schetter, Nicole Verhey-Van-Wijk, Jörg Schlossherr, Marlis Steinbüchel and Martin Gajewski

Int. J. Dev. Biol. (2003) 47: 439-450

\section{Ca2+-ions and pattern control in Hydra}

Stefanie Zeretzke, Fernando Pérez, Kirsten Velden and Stefan Berking

Int. J. Dev. Biol. (2002) 46: 705-710

Autoaggressive, multi-headed and other mutant phenotypes in Hydractinia echinata (Cnidaria: Hydrozoa)

Werner A Müller

Int. J. Dev. Biol. (2002) 46: 1023-1033

Pattern regulation properties of a Hydra strain which produces additional heads along the body axis

S Zeretzke and S Berking

Int. J. Dev. Biol. (2001) 45: 431-439

5 yr ISI Impact Factor $(2010)=2.961$

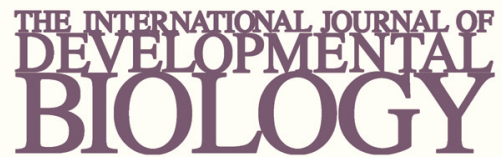

Volume 54 Nos. 6/7
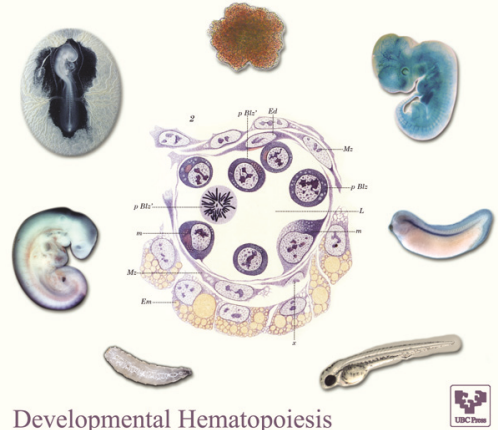

Special Issue
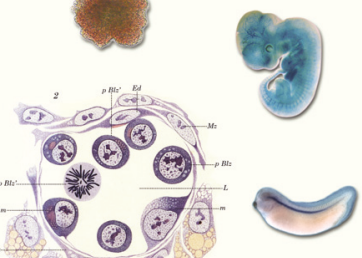

Developmental Hematopoiesis
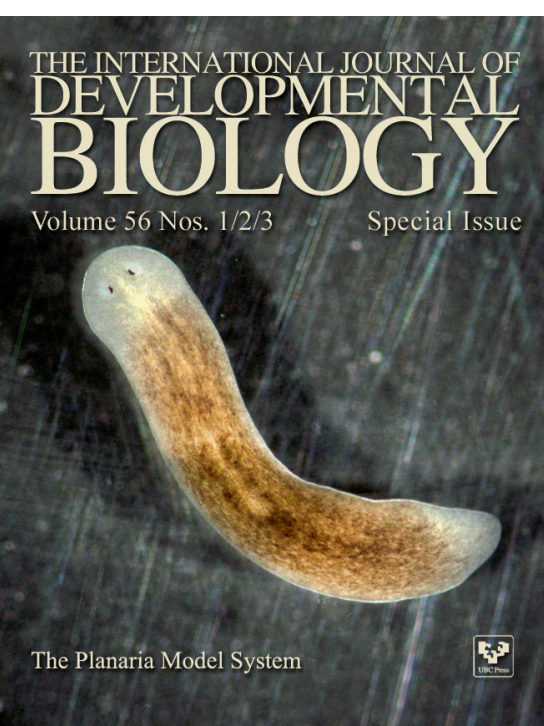
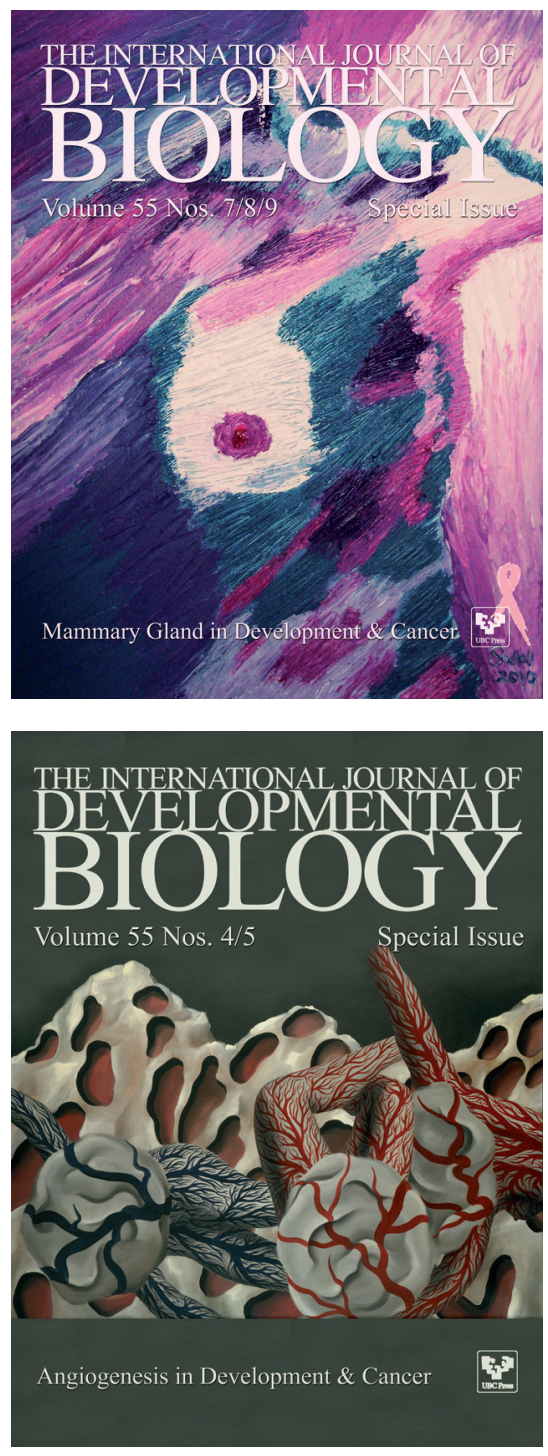